Check for updates

Cite this as: $B M J 2020 ; 370: m 3668$ http://dx.doi.org/10.1136/bmj.m3668 Published: 30 September 2020

\section{Measuring multimorbidity beyond counting diseases: systematic review of community and population studies and guide to index choice}

The supplementary file for this paper by Stirland and colleagues (BMJ 2020;368:m16o, doi:, published 18 February 2020) has been amended. The reference list needed to be updated because several of the links were incorrect, and in eTable 10 the first row for the Multimorbidity Weighted Index has been changed: the performance details now appear in the column headed "Additional outcomes tested in external validation" and the column headed "Performance (original outcomes)" has been clarified by including the text "No outcomes in original paper (physical functioning score used as weighting).” 